\title{
Monitoring the effects of biocide treatment of Pseudomonas fluorescens biofilms formed under different flow regimes
}

\author{
M. Simões, M.O. Pereira and M.J. Vieira \\ Centro de Engenharia Biológica - IBQF, Universidade do Minho, 4710-057 Braga, Portugal
}

\begin{abstract}
The effectiveness of glutaraldehyde (GTA), a very common biocide for controlling biofilms formed by Pseudomonas fluorescens on stainless steel slides, in laminar and turbulent flow, was investigated. Tests were performed using a concentration of biocide of $200 \mathrm{mg} \mathrm{L}^{-1}$ and a range of exposure times. The GTA action was assessed by means of activity tests and dry weight of the biofilms. The physical stability of the biofilm without biocide application and after exposure to GTA for different periods of time was also studied and evaluated through the variation of the mass of the deposit after submission to different rotation velocities. The results showed that, in all the situations studied, biofilms were not controlled after the treatment with biocide, since they remained on the metal surface and were still active. The results also demonstrated that the physical stability of the biofilms increased with biocide application.
\end{abstract}

Keywords Biocide efficacy; biofilm monitoring; flow regime; glutaraldehyde; physical stability

\section{Introduction}

The unwanted accumulation of biofilms in industrial equipment in aqueous environments biofouling - is a natural occurrence. Biocides still represent the more significant countermeasure to control biofilm formation. However, these chemical substances may kill the microorganisms but are not fully effective in removing the biofilm, leaving biomass in the surface. This fact may enhance microbial regrowth. Thus, to increase the biocide concentration applied, to use new protocols of application or to change to other agents are the more frequent practices used to overcome the problem.

Glutaraldehyde (GTA) is one of the biocides widely used in industry. Its biocidal effect is attributed to its two aldehyde groups, which can interact with microbial cell constituents, reacting with ammonia and primary amines and more slowly with secondary amines, binding strongly to outer cellular layers (Eager et al., 1986; Cloete et al., 1998).

The aim of this work was to clarify the mode of action of the GTA on biofilms formed by Pseudomonas fluorescens, an abundant bacteria in biofilms formed in industrial equipment, under laminar and turbulent flow. The experimental tests were performed using $200 \mathrm{mg} \mathrm{L}^{-1}$ of GTA and a range of exposure times. The efficiency of the biocide for controlling biofilm accumulation must be tested in systems that mimic industrial conditions. For that, a continuous monitoring of the biofilm before and after biocide application was carried out, by using a simple flow cell reactor (Pereira et al., 2002) that allows biofilm sampling without disturbing the system. Additionally, the physical stability of the biofilm before and after biocide application was assessed by using a rotating device.

\section{Material and methods}

Microorganism. Throughout this work Pseudomonas fluorescens ATCC 13525 was used.

Biocide. A non-oxidising biocide solution of glutaraldehyde (Reidel-de Haën 62621) in water was used as stock solution. The biocide concentration tested was $200 \mathrm{mg} \mathrm{L}^{-1}$. 
Flow cell reactor. A flow cell described elsewhere (Pereira et al., 2002) was used as a biofilm formation apparatus. It consists of a semi-circular PMMA duct with several apertures on its flat face to fit several coupons where biofilm formation surfaces $(1.75 \mathrm{~cm} \times$ $1.25 \mathrm{~cm}$ ) were glued. These surfaces, which in the case under study are ASI 316 stainless steel slides, are in contact with the fluid circulating in the system. Two flow cells were operated in parallel, to obtain one cell working under laminar flow $\left(\operatorname{Re}=2,000, \mathrm{u}=0.204 \mathrm{~m} \mathrm{~s}^{-1}\right)$ and the other cell under turbulent flow $\left(\operatorname{Re}=5,200, \mathrm{u}=0.532 \mathrm{~m} \mathrm{~s}^{-1}\right)$. The system was continuously fed with sterile medium containing $50 \mathrm{mg} \mathrm{L}^{-1}$ glucose, $25 \mathrm{mg} \mathrm{L}^{-1}$ peptone, 12.5 $\mathrm{mg} \mathrm{L}^{-1}$ yeast extract in phosphate buffer $(\mathrm{pH} 7)$ and Pseudomonas fluorescens in the exponential phase of growth. The biofilm was allowed to grow for 7 days before the beginning of the treatment.

Biocide treatment. Before the treatment three coupons of each flow cell were removed and used as a control. During the treatment period, the suspension flowing in the system was replaced by a solution of GTA, $200 \mathrm{mg} \mathrm{L}^{-1}$. Several experiments were carried out: the system was exposed to the biocide during 1 hour, 2 hours, 2 times $1 / 2$ hour, and 2 times 1 hour. In the case of multiple applications, they were spaced 2 hours apart. The suspension of bacteria and nutrients was re-introduced in the system between biocide applications and at the end of the treatment. The biofilms were sampled at the end of the exposure period to the biocide and after 3 hours. Each experiment was repeated three times.

Scrapping and disaggregation of the biofilms. The biofilm that covered the metal slides was completely scraped off the metal and resuspended into $10 \mathrm{~mL}$ of phosphate buffer $(\mathrm{pH}$ 7). The homogenised suspensions of biofilms were used to assess the cellular activity of the biofilm by means of oxygen uptake rates. The biofilm suspensions that were not treated with GTA were also used to determine the total and extracellular macromolecular composition of the biofilm.

Analytical methods. The chemical analyses were carried out on the homogenised biofilm suspensions, before biocide treatment. The proteins were determined using the Lowry modified method (SIGMA-Protein Kit P5656) and the polysaccharides by the phenolsulphuric acid method of Dubois et al. (1956).

Biofilm mass quantification. The dry biofilm mass was assessed by the determination of the total volatile solids (TVS) of the homogenised biofilm suspensions, according to the Standard Methods (1989). The biofilm mass accumulated on the several slides was expressed in $\mathrm{g}$ of TVS per $\mathrm{cm}^{2}$ of surface area of the metal slide.

Biofilm removal. The biocide action on biofilms formed on the metal slides was studied by the assessment of the variation of the dry biofilm mass of the deposit due to the biocide treatment and expressed as a percentage.

Physical stability of the biofilm. The physical stability of the biofilms was assessed by means of submitting the biofilms to increasing rotating speeds and determining the biomass loss, in an apparatus similar to the one used by Azeredo and Oliveira (2000). Three ASI 316 stainless steel cylinders were inserted in a $3 \mathrm{~L}$ reactor, operating under the same growth conditions as the flow cells. The cylinders were rotating at $300 \mathrm{rpm}$. After 7 days of operation, the cylinders covered with biofilm were carefully removed from the reactor. One of the cylinders was immersed in a reactor with phosphate buffer $(\mathrm{pH} 7)$ while the others were 
immersed in reactors containing a $200 \mathrm{mg} \mathrm{L}^{-1}$ of GTA solution (volume of the reactors $170 \mathrm{~mL})$. The cylinders were rotating at $300 \mathrm{rpm}$ during the biocide treatment $(1 / 2$ hour, 1 hour and 2 hours). After the exposure to the biocide the cylinders were subjected to serial velocities of rotation $-500,1,000,1,500$, and 2,000 rpm for a period of 30 seconds. The weight of the cylinders was determined before the immersion and after each rotation. The experiments were repeated three times, at least.

\section{Experiments with planktonic bacteria}

Microorganism growth. A continuous pure culture of the $P$. fluorescens bacteria as described elsewhere (Pereira et al., 1998) was used as the test microorganism. A continuous pure culture of the bacteria was grown in a $2 \mathrm{~L}$ glass fermenter, at $27 \pm 1{ }^{\circ} \mathrm{C}$, suitably aerated and magnetically agitated. The fermenter was continuously fed with $0.05 \mathrm{~L} \mathrm{~h}^{-1}$ of sterile medium containing $5 \mathrm{~g} \mathrm{~L}^{-1}$ glucose, $2.5 \mathrm{~g} \mathrm{~L}^{-1}$ peptone and $1.25 \mathrm{~g} \mathrm{~L}^{-1}$ yeast extract in phosphate buffer ( $\mathrm{pH} 7$ ).

Biocide treatment. Periodically, a suitable amount of $P$. fluorescens culture was removed from the fermenter, centrifuged $(3,777 \mathrm{~g}, 5 \mathrm{~min})$ and washed three times with saline phosphate buffer $(\mathrm{pH} 7,0.01 \mathrm{M})$. The pellets were ressuspended in phosphate buffer $(\mathrm{pH} 7)$ in order to obtain a bacterial culture with an optical density of $0.4(\lambda=640 \mathrm{~nm})$. Portions of the culture were added to several sterilised glass flasks and put in an orbital shaker (120 rpm). The culture was exposed to a range of biocide concentrations between 0.2 and $13 \mathrm{mg} \mathrm{L}^{-1}$, and the bacterial respiratory activity was assessed 30 minutes after biocide addition through oxygen consumption in a respiration chamber.

To investigate the influence of the proteins on the biocide efficacy, the procedure described above was followed but with the addition of $3 \mathrm{~g} \mathrm{~L}^{-1}$ of bovine serum albumin, BSA (Merck 12018), to the bacterial culture.

Oxygen uptake rate. The respiratory activity of the several samples was evaluated by measuring oxygen uptake rates in a biological oxygen monitor (BOM) in short-term assays. The assays were performed in a Yellow Springs Instruments BOM (Model 53) and the procedure used has been described elsewhere (Pereira et al., 1998).

\section{Results}

The action of GTA against biofilms formed under laminar and turbulent flow on stainless steel slides was studied by the assessment of the variation of the mass of the deposit, the determination of the respiratory activity and the physical stability of the deposit after each biocide treatment. For each test, the appropriate control experiments were carried out.

Figure 1 presents photographs of coupons with stainless steel slides covered with biofilm developed under different flow regimes.

Table 1 presents the characteristics of the Pseudomonas fluorescens biofilms developed under turbulent and laminar flow.

Figures 2 and 3 present, respectively, the percentage of biofilm removal and the percentage of inactivation due to each GTA treatment for turbulent and laminar flow.

The interference of BSA with the efficacy of GTA against the suspended bacterial cultures can be seen in Figure 4.

The results of the physical stability of the biofilm, expressed in terms of percentage of the biofilm that remains on the metal surface for the conditions tested, are presented in Figure 5.

The results obtained showed that: (i) the structure of biofilms depends on the flow condition: while the biofilm formed under turbulent flow is homogeneous and slimy, the one 


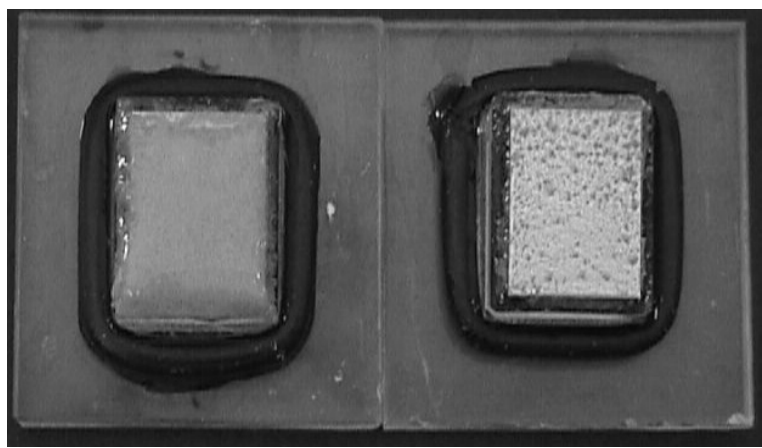

(a)

(b)

Figure 1 Photograph of the coupons with biofilms formed on the stainless steel slide in: (a) turbulent, (b) laminar flow

Table 1 Characteristics of Pseudomonas fluorescens biofilms grown under turbulent and laminar flow. Mean values \pm confidence interval of $95 \%$

\begin{tabular}{|c|c|c|c|c|}
\hline Flow & $\begin{array}{c}\text { Biofilm mass } \\
\left(\mathbf{m g} / \mathrm{cm}^{2}\right)\end{array}$ & $\begin{array}{c}\text { Biofilm activity } \\
\left(\mathrm{mg} \mathrm{O}_{2} / \mathrm{g}_{\text {biofilm }} \cdot \mathrm{min}\right)\end{array}$ & $\begin{array}{l}\text { Total protein } \\
\left(\mathbf{m g} / \mathbf{g}_{\text {biofilm }}\right)\end{array}$ & $\begin{array}{c}\text { Total polysaccharide } \\
\left(\mathbf{m g} / \mathbf{g}_{\text {biofilm }}\right)\end{array}$ \\
\hline Turbulent & $1.55( \pm 0.20)$ & $0.27( \pm 0.09)$ & $261( \pm 41)$ & $151( \pm 29)$ \\
\hline Laminar & $0.78( \pm 0.15)$ & $0.06( \pm 0.02)$ & $128( \pm 23)$ & $196( \pm 76)$ \\
\hline
\end{tabular}

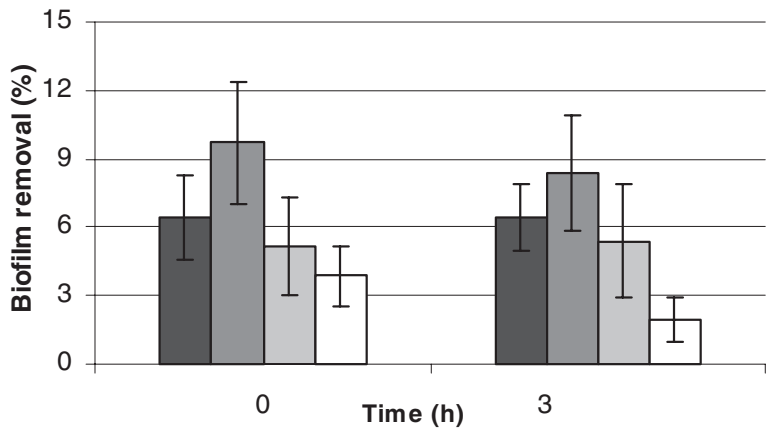

$\square 1$ hour $\square 2$ hours $\square 2^{*} 1 / 2$ hour $\square 2^{*} 1$ hour

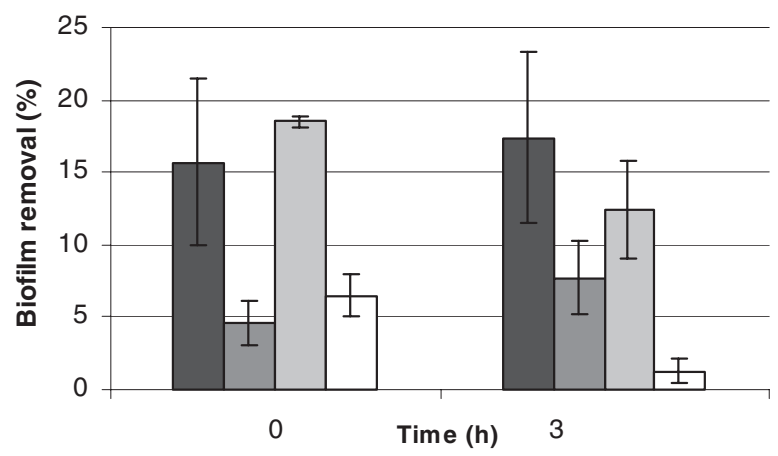

$\square 1$ hour $\square 2$ hours $\square 2^{*} 1 / 2$ hour $\square 2^{*} 1$ hour

Figure 2 Biofilm removal (expresses the loss of dry mass of the biofilm) after GTA application as function of time (bars represent the standard deviation): (a) turbulent flow, (b) laminar flow 


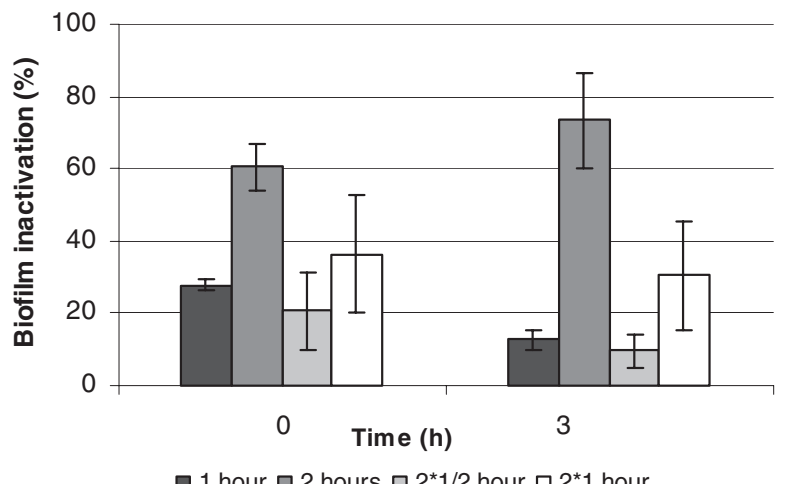

(a)

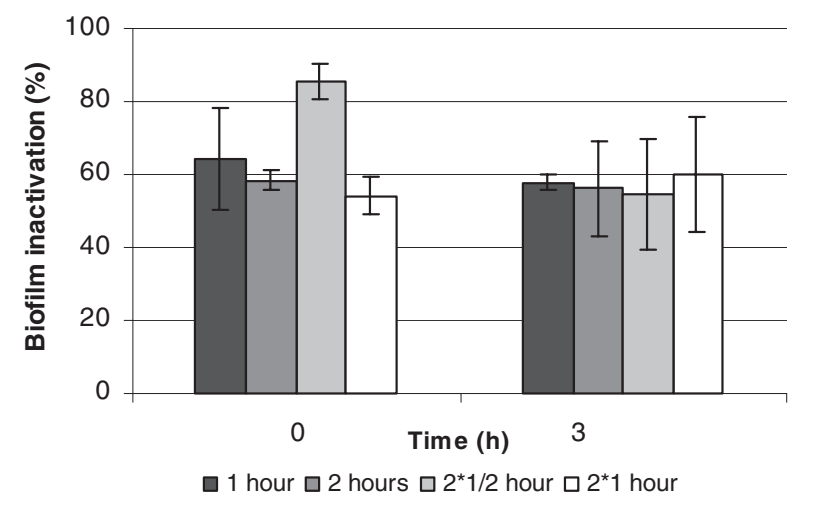

(b)

Figure 3 Biofilm inactivation after GTA application as function of time (bars represent the standard deviation): (a) turbulent flow, (b) laminar flow

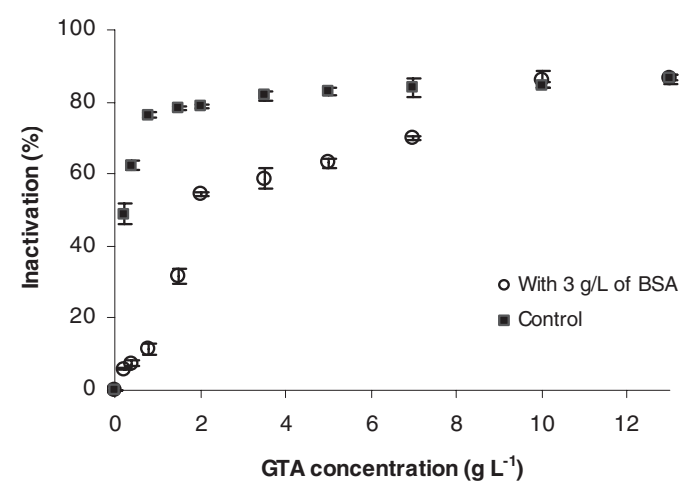

Figure 4 Inactivation of the respiratory activity of the bacterial suspended cultures after treatment with several concentrations of GTA, with and without (control) BSA addition

formed under laminar flow is scattered on the surface (Figure 1); (ii) the characterisation of Pseudomonas fluorescens biofilms (Table 1) shows that the biofilms formed under turbulent flow are more active, have a less polysaccharide amount per $\mathrm{g}$ of biofilm and have a higher protein content; (iii) biofilms were not removed after the GTA treatment, in all the situations studied (Figure 2); (iv) the effect of the biocide is dependent on the flow regime under which the biofilm was formed; (v) the biocide proved to be more effective for longer 


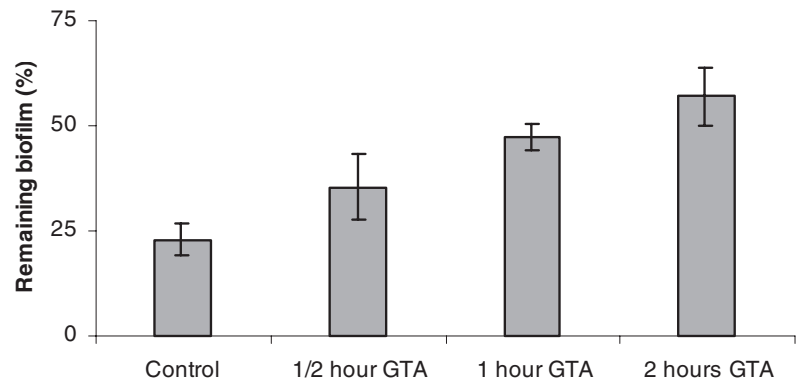

Figure 5 Percentage of biofilm remaining on the surface after submitting them to different rotation speeds

exposure times (Figure 3); (vi) for the same total exposure time, the multiple application of biocide proved to be less efficient than the application in a single period of time; (vii) the GTA efficacy was significantly reduced when the BSA was introduced in the suspended bacterial cultures, this reduction being particularly noticeable for GTA concentrations less than $5 \mathrm{~g} \mathrm{~L}^{-1}$ (Figure 4); (viii) the physical stability increases with the exposure time to the biocide (Figure 5) since less biofilm was removed from the metal surface after exposure to very high rotation rates.

\section{Discussion}

The results show that the flow regime under which the biofilm is formed has a strong impact on biocide action: biofilms formed under laminar flow are more easily inactivated that the ones formed under turbulent flow (Figure 3). Biofilms formed under turbulent flow are denser, have a stronger EPS matrix; conversely, laminar biofilms are scattered on the surface and appear to have protuberances (Figure 1) (Vieira et al., 1993). As a consequence, GTA may more easily penetrate the biofilms formed under laminar flow. Additionally, biofilms formed in turbulent flow have a higher protein content (Table 1) that can react with the GTA, lowering the GTA available to inactivate the bacterial cells.

The results illustrated in Figure 4 corroborate this last assumption. In fact, in the presence of a protein, in this case BSA, the respiratory bacterial inactivation resulting from the application of $200 \mathrm{mg} \mathrm{L}^{-1}$ of GTA (about $80 \%$ after 30 minutes of contact with GTA in the absence of BSA) was drastically reduced. It is known that BSA contains glycine, lysine and histidine and that histidine has been suggested as a neutraliser of GTA in the European Standard Test (Walsh et al., 1999). In a previous work, Pereira and Vieira (2001) also suggested that when GTA was applied to control biofilms under an undefined flow regime it reacted with the proteins of the polymeric matrix, besides the reaction with the bacterial cells. As a consequence, the concentration of biocide available for killing the cells is reduced and thus, the action of the biocide is lower than in the suspension tests as has been pointed out by Pereira and Vieira (2001).

From Table 1, it seems to be possible to deduce that the biofilms formed under turbulent flow entrap more bacterial cells than those developed under laminar conditions, since the specific respiratory activity of the turbulent biofilms is considerably higher as well as the total protein content.

An important conclusion is that it was not possible to reduce the mass of biofilm accumulated on the surface, and that the physical stability of the biofilms increased with biocide application. This fact can be explained by the ability of GTA to cross-link proteins, expressed as a fixative action of the biofilm to the surface. This is not surprising since GTA is used as fixation agent in microscopy.

In general, higher biofilm removal from the surface is obtained for shorter exposure times to the biocide, but less biofilm is removed when compared with the control. This 
result may be associated with the higher physical stability of the biofilms obtained after the application of the biocide, related, probably, to the fixative action of GTA.

\section{Conclusions}

From the results presented it can be concluded that the experimental systems used here, i.e. the flow cell reactors and the rotating device, are suitable for the evaluation of biofilm growth, and represent very useful tools to monitor the behaviour of biofilms after biocide treatment, as suggested by Pereira et al. (2002).

\section{Acknowledgements}

The authors acknowledge the financial support provided by IBQF, and the Portuguese Foundation for Science and Technology (Project POCTI/1999/BIO/35683 and PhD grant for Manuel Simões).

\section{References}

Angell, P., Arrage, A.A., Mittelman, M.W. and White, D.C. (1993). On-line, non-destructive biomass determination of bacterial biofilms by fluorometry. J. Microbiol. Methods, 18, 317-327.

APHA, AWWA, WPCF (1989). Standard Methods for the Examination of Water and Wastewater. 17th edition, Clesceri, L.S., Greenberg, A.E. and Trussel, R.R. eds. American Public Health Association, Washington DC, USA.

Azeredo, J. and Oliveira, R. (2000). The role of exopolymers produced by Sphingomonas paucimobilis in biofilm formation and composition, Biofouling, 16(1), 17-27.

Cloete, T.E., Jacobs, L. and Bröxel, V.S. (1998). The chemical control of biofouling in industrial water systems. Biodegradation, 23-37.

Costerton, J.W., Cheng, K.J. and Geesey, G.G. (1987). Bacterial Biofilms in Nature and Disease. Ann. Rev. Microbiol., 41, 435-464.

Dubois, M., Gilles, K.A., Hamilton, J.K., Rebers, A. and Smith, F. (1956). Colorimetric method for determination of sugars and related substances. Anal. Chem., 28, 350-356.

Eager, R.G., Leder, J. and Theis, A.B. (1986). Glutaraldehyde: factors important for microbiocidal efficacy. 3rd Conference on progress in chemical disinfection, Binghamton, NY, 3-5 April.

Pereira, M.O., Vieira, M.J., Beleza, V.M. and Melo, L.F. (1998). Retention of bacteria in cellulose fibres as a means of reducing biofouling in paper pulp production processes. Biofouling, 13(1), 1-18.

Pereira, M.O. and Vieira, M.J. (2001). Effects of the interactions glutaraldehyde-polymeric matrix on the efficacy of the biocide on Pseudomonas fluorescens biofilms. Biofouling, 12(2), 93-101.

Pereira, M.O., Morin, P., Vieira, M.J. and Melo, L.F. (2002). A versatile reactor for continuous monitoring of biofilm properties in laboratory and industrial conditions. Lett. Appl. Microbiol., 34, 22-26.

Vieira, M.J., Melo, L.F. and Pinheiro, M.M. (1993). Biofilm formation - hydrodynamic effects on internal diffusion and structure. Biofouling, 7(1), 67-80.

Walsh, S.E., Maillard, J.-Y., Simons, C. and Russel, A.D. (1999). Studies on the mechanisms of the antimicrobial action of ortho-phthaldehyde. J. Appl. Microbiol., 87, 702-710. 